The book is fairly short (267 pages) and has the merit of being easy to read. Resident anaesthetists and ear, nose and throat house surgeons should find much valuable information in it.

C.C.C.

\section{AN INTRODUCTION TO EXPERIMENTAL SURGICAL STUDIES}

By W. J. Dempster, F.R.C.S. Pp. 463, with $7 \mathrm{r}$ illustrations. Oxford: Blackwell Scientific Publications. 1957. 50s.

With the present day development of surgery as a science there has been a great increase in experimental surgery, both as a means of inquiry into the pathogenesis of a variety of disorders and for the detection and solution of problems in new surgical techniques prior to human application. The author of this book attempts to provide for the younger surgeon a wide range of references and a critical commentary in this field.

The sections on wound healing, organ and tissue transplantation and genito-urinary problems occupy over half the book and are on the whole sound and comprehensive. In other fields discussed with which the author is perhaps less familiar the test is not so reliable. The lack of reference under the heading of heart-lung substitutes to the modern Gibbon machine, in practice probably the most successful, is most notable and it is doubtful if vascular surgeons would accept the statement that they have abandoned the use of homografts in favour of nylon substitutes.

A few such imperfections are to be expected in any new book of this scope and do not detract from its value as a reference source to those engaged in experimental surgery.

J.L.

\section{CHEMICAL METHODS IN CLINICAL MEDICINE}

By G. A. HarRison, M.D., F.R.I.C. Fourth Edition. Pp. 667, figs. 158. London: J. \& A. Churchill Ltd. 65 s.

Ten years have elapsed since the last edition of this standard work appeared. Dr. Harrison has added a great deal of new material but managed to compress it into few extra pages. There are welcome new accounts of photoelectric absorptiometers and of the flame photometer (it is a pity that the author still clings to milligrams in describing sodium and potassium standards). Chromatography and electrophoresis are described. The author's prejudice against the estimation of the r 7-Ketosteroids in urine seems hard to justify. Here and there certain changes of fashion might have led to changes of emphasis: few clinicians now bother with the urea concentration test for example, while PSP excretion, which is dismissed in three lines, is estimated in most American laboratories. The author's views on diabetes are unorthodox: it is surprising to find that mild diabetics should either be warned not to lose weight (p. 193) or told to maintain it (p. 194) when a large number of obese patients with glycosuria regain normal carbohydrate tolerance when weight is reduced, a fact which is not mentioned. The section on diabetic coma is valueless and would be better omitted. There is a short section on intravenous fluids; it might with advantage include some notes on potassium therapy; the author's only reference to a paper on postoperative fluid and electrolyte therapy is dated 1938 . The section on liver function tests is more topical, but most workers would like to see a description of the thymol turbidity test included, though the author appears to have no use for it.

These shortcomings do not detract from the value of the book as a whole. Comprehensive and clearly written, beautifully produced and inexpensive, it must remain a necessary standby in every routine laboratory.

\section{THE MAMMALIAN CEREBRAL CORTEX}

By B. Delisle Burns, B.A., M.R.C.S., L.R.C.P. Pp. vii + II9, with 24 diagrams. London: Edward Arnold Ltd. I958. 2 is.

This book, which is the fifth of the recent series of Monographs by the Physiological Society, is slightly unfortunately named. The work reviewedo and described is mainly concerned with the isolatedo cerebral cortex, which means that a piece of cortex $20 \mathrm{~mm}$. long and $5 \mathrm{~mm}$. wide and $4 \mathrm{~mm}$. deep is studied in an animal that has already been decerebrated at the level of the tentorium. While Dr. Delisle Burns does not confine himself in his discussion to this preparation he is mainly concerned with results arising from this.

It should be stated, however, that the book is extremely clear. The author does not try and hide our present ignorance behind a barrage of technology and while he discusses memory and other difficult subjects, he tries to base his argument on the results which are available and is in search, as he says, of 'the cellular machinery of memory.'

Within these limitations the reviewer would strongly recommend this book to neurologists who are trying to come to grips with this most difficult part of their subject.

\section{STEDMAN'S MEDICAL DICTIONARY}

Edited by N. B. TAYLOR, V.D., M.D., F.R.C.S., F.R.C.P. Nineteenth edition. Pp. xlvi + I,656, illustrated. London: Baillière, Tindall \& Cox Ltd. 1957. 88s.

The nineteenth edition maintains the standard of that of 1954, with the inevitable addition of several thousand new medical terms and a hundred pages. Two of the outstanding features of this dictionary are the section on medical etymology and the 
number of structural formulae given. In common with most medical dictionaries, however, the illustrations are both profuse and too often unnecessary. In the interests of space these might be reserved for those terms not readily made comprehensible by verbal description.

J.L.

\section{MEDICAL TREATMENT}

By Kenneth Maclean, M.A., M.D., F.R.C.P., with chapters on the Tropical Diseases by Col. W. R. M. Drew, C.B.E., F.R.C.P., D.T.M. and H. Pp. 696. London: J. \& A. Churchill Ltd. I957. 50s.

This is a large and very comprehensive new textbook of medical treatment. The author has given a concise account of modern therapy, and the material is easily accessible. There are a number of recent references and a good index. The book is well produced and not expensive. Anyone requiring a reliable guide to medical treatment will find it an excellent investment. It is always questionable, however, whether such a textbook should include introductory paragraphs on diagnosis. It might be argued that if the physician has not decided what is wrong with the patient he should be consulting a textbook of medicine, not one of treatment. At best, such paragraphs cannot deal adequately with the problems raised, and they make the book a good deal longer than it would otherwise have been. Dr. MacLean has included notes on differential diagnosis and it seems probable that in doing so he was guided by the hope that the book would prove valuable to general practitioners, house officers and senior students, as he states in his preface. Certainly, students taking examinations will find these brief observations on diagnosis valuable in linking their facts together, and busy general practitioners will be glad of a brief reminder of the diagnostic pitfalls they have to avoid, but it seems probable that the space taken up in this wav could have been more usefully given to a fuller account of therapeutic measures themselves.

There are some irritating minor mistakes which need correction in the next edition, e.g. $17.3 \mathrm{~g}$. is given as roo per cent. $\mathrm{Hb}$. on the Sahli Scale; fruit is said to be a good source of iron; on p. 217 starch is apparently not considered as carbohydrate; the Law of Mass Action is ascribed to Henderson (what about Hasselbalch anyway?), this equation being only one particular application of it. The author advises the restriction of the fluid intake in cardiac failure to 'between 30 and $40 \mathrm{oz}$. in the 24 hours.' He stresses the danger of giving digitalis after myocardial infarction, and deals with digitalis and quinidine as though they were more or less equi- valent alternative ' cardiac drugs.' This approach leads to the omission of any reference to the importance of digitalization before attempting to bring about reversion to normal rhythm with quinidine.

The book includes chapters on mental illness in general practice (a brief but sensible account), on skin diseases, on tropical medicine and on acute poisoning. There are also special chapters on fluid and electrolyte disturbances, on steroid hormones and on antibiotics, which give concise and reliable summaries of modern views (it is a pity that the greater safety and efficacy of soluble penicillin compared with long acting preparations is not stressed. The prophylactic use of oral penicillin is described on p. 37 , when sulphadiazine is mentioned, most surprisingly, as a satisfactory alternative). A textbook as comprehensive as this one might well include a chapter on dietary therapy. This is a subject of great importance in general practice; as it is there are 80 separate entries under Diet in the index, and it might be thought that a general discussion of the subject would be helpful.

A very grreat amount of labour and thought has evidently rone into this book, and it deserves to be successful. It is to be hoped that the author will have the time and energy to devote to the frequent revisions tl:at will be necessary if that success is to be maintainec.

We wish to announce the publication of a new journal, Transactions of the Colleges of Physicians, Surgeons, Obstetricians and Gynaecologists of South Africa. It is edited by Arthur J. Helfet and published by the College of Physicians and Surgeons of South Africa, P.O. Box I 20, Cape Town.

The publication of a new journal, Bulletin of Polish Medical History and Science is announced. It is edited by Alexander Rytel and published by the Polish Medical Alliance, 2424 N. Kedzie Avenue, Chicago 47, Illinois, U.S.A.

We have pleasure in announcing the publication of the first issue of a new journal, Immunology, which is the official journal of the British Society for Immunology. It is published by Blackwell Scientific Publications of Oxford and it is to be issued quarterly at an annual subscription of 605 . post free. The first number appeared in January of this year. 